\title{
Could university training and a proactive attitude of coworkers be associated with influenza vaccination compliance? A multicentre survey among Italian medical residents
}

\author{
Claudio Costantino*, Emanuele Amodio, Giuseppe Calamusa, Francesco Vitale and Walter Mazzucco
}

\begin{abstract}
Background: Although influenza vaccination has been demonstrated to be safe and effective, vaccination coverage rates among health care workers and among medical residents appear generally low. Several investigations have been performed worldwide to analyze the healthcare workers' educational deficiencies.

This multicentre survey aimed to investigate at a nationwide level training quality and work environment associated with seasonal influenza vaccination uptake among Italian medical residents.

Methods: A retrospective cohort study was carried out from April 2012 to June 2012 on medical residents regularly attending the post-graduate medical schools of 18 Italian Universities via an anonymous, self administered, webbased questionnaire. Data have been analyzed by using the $\mathrm{R}$ statistical software package.

Results: A total of 2506 out of 10,854 medical residents (23.1\%) have been recruited. The quality of training on influenza and influenza vaccination was reported as "fair" or "poor" during both pre-graduate $(40.7 \%$ of respondents) and post-graduate medical school (59.6\% of respondents).

Vaccination uptake was associated with adherence to seasonal 2011/2012 influenza vaccination of medical school tutors (adjusted $\mathrm{OR}=4.4 ; 95 \% \mathrm{Cl}=1.35-14.26$ ) and other medical residents (adjusted $\mathrm{OR}=2.2 ; 95 \% \mathrm{Cl}=1.14-4.23$ ). Moreover, influenza vaccination uptake was also associated with correct knowledge about the virus composition of $2011 / 2012$ influenza vaccine (adjusted $\mathrm{OR}=2.43 ; 95 \% \mathrm{Cl}=1.64-2.58$ ) and consultation of scientific sources or Institutional recommendations on influenza vaccination (adjusted $\mathrm{OR}=6.96 ; 95 \% \mathrm{Cl}=3.38-214.36$ ).

Conclusions: Medical residency represents an opportunity to implement educational and training interventions aiming to promote appropriate professional behaviors and skills. Our study suggest that appropriate training, adequate education and proactive coworkers feelings can improve influenza vaccination attitudes towards young doctor.
\end{abstract}

Keywords: Influenza vaccination, Medical residents, Multicentre survey, Coworkers attitude, University training

\footnotetext{
* Correspondence: claudio.costantino01@unipa.it

Department of Science for Health Promotion and Mother to Child Care G.

D'Alessandro, University of Palermo, Via del Vespro n 133, ZIP code 90127

Palermo, Italy
} 


\section{Background}

Influenza vaccination is universally recognized as the essential intervention to limit the spread of the virus particularly among elderly and patients with comorbidities [1, 2].

Moreover, during annual influenza epidemics, vaccination of the health care workers can contribute to reduce both the spread of the virus to defenceless patients and the absence from work $[3,4]$.

Unfortunately, despite influenza vaccine has been demonstrated to be safe and effective in healthy persons under 65 years of age, providing $70 \%$ to $90 \%$ protection against infection, influenza vaccination uptake rates observed in different studies among health care workers appear generally low, far away from the recommended rate of $75 \%$ [5-8].

Recently, some studies have examined the influenza vaccination coverage among medical residents and general practitioner trainee physicians in the Italian setting, documenting very low coverage rates $(<30 \%)$, in line with other studies conducted worldwide [9-14].

Although health care workers generally recognize the fundamental role of promoting influenza vaccination, in the last years there is an intense debate on the effectiveness of mandatory vaccination among health care workers, especially for its ethical and legal implications [15-17].

Nevertheless, several investigations have been performed at a local level to analyze the healthcare workers' educational deficiencies and the correlations with the actions taken by public health authorities to implement vaccination rates, however no study has systemized and analyzed such results at a nationwide level [18, 19].

According to the previous considerations, the Italian Medical Residents Influenza Vaccination working group aimed to investigate, via a multicentre web-based survey, training quality, work environment and knowledge associated with seasonal influenza vaccination uptake among Italian medical residents.

\section{Methods}

This retrospective cohort study was carried out on medical residents regularly attending the post-graduate schools of 18 Italian Universities (Bari, Bologna, Brescia, Catania, Catanzaro, Chieti, L'Aquila, Messina, Modena, Napoli Federico II, Palermo, Pavia, Parma, Roma Cattolica, Roma Tor Vergata, Siena, Torino, Verona).

Email addresses of each medical resident were requested and obtained from the Universities information Centers. Medical residents without at least one valid email address were excluded from the study.

Each medical resident included in the study was recruited from April 2012 to June 2012 by receiving an e-mail containing an explanation of the study objectives, an informed consent form and a link to an anonymous, self administered, web-based questionnaire.
The study was approved by the Institutional Review Board of the AOUP "P. Giaccone" Palermo, Italy.

\section{Questionnaire}

The questionnaire was designed by the Italian Medical Residents Influenza Vaccination working group. The first version of the questionnaire was validated in a pilot study carried out on 100 medical residents attending post-graduate medical schools at the University of Palermo. The final version of the questionnaire encompassed 10 sections including 23 items. Data concerning vaccination coverage, reasons of influenza vaccination uptake and refusing, as well as attitudes to recommend influenza vaccination to patients, were analyzed elsewhere [20].

In the present study, we have focused on data related to university and post-graduate training and work environment as reported below:

1) Demographic characteristics: sex, age, year of graduation, year of residency, specialty duties (categorized according to Italian legislation as "Clinical duties" including Allergy and immunology, Cardiology, Dermatology, Endocrinology, Gastroenterology, Geriatrics, Infectious disease, Nephrology, Neurology, Oncology, Pediatrics, Physiatry, Psychiatry, Pulmonology, Rheumatology; "Surgical duties" including Cardiovascular surgery, General surgery, Gynecology, Maxillofacial surgery, Neurosurgery, Ophthalmology, Otolaryngology, Orthopedic surgery, Pediatric surgery, Plastic surgery, Surgical oncology, Thoracic surgery, Urology, Vascular surgery; "Diagnostic duties" including Hygiene and Preventive Medicine, Anesthesiology, Clinical laboratory sciences, Microbiology, Emergency medicine, Forensic Medicine, Intensive care medicine, Pathology, Radiology, Occupational Medicine), geographic setting (categorized as "North", "Centre" and "South" of Italy);

2) Adherence to $2011 / 2012$ influenza vaccination among coworkers (post graduate medical school tutors and other medical residents): categorized as "Yes, $\leq 90 \%$ of tutors/ medical residents", "Yes, $\leq 50 \%$ of tutors/ medical residents", "Yes, $\geq 25 \%$ of tutors/ medical residents", "None of tutors/ medical residents", "I don't know"

3) Training quality on influenza and its vaccination during degree and post graduate medical school: investigated by closed ended question, categorized as "excellent", "good", "satisfactory", "fair", "poor";

4) Knowledge about the influenza vaccine virus assortment for 2011-2012 season: investigated by closed ended questions categorized as "AH1N1, 
AH3N2 and B" (correct answer), "AH1N1, AH5N1, B", "AH1N1 and H3N2" and "AH3N2 and B" (wrong answers), "I don't know";

5) Main informative sources on influenza/influenza vaccination: categorized as "none", "not interested in any information sources", "recommendation of National Health Minister", "recommendation of International Health Authorities", "scientific sources" and "mass media", "internet (facebook, twitter, blog, youtube)", "word of mouth among health care workers", "other".

\section{Statistical analysis}

Absolute and relative frequencies have been calculated for qualitative variables, while quantitative variables were summarized as median (interquartile range). Categorical variables were analyzed using the chi-square test (Mantel-Haenszel) and medians were compared by using the Mann-Whitney-Wilcoxon test. All variables were found to have a statistically significant association (two-tailed p-value $<0.05$ ) with vaccine uptake in the univariate analysis have been included in a backward stepwise logistic-regression model. Goodness of fit was calculated for each model, and the model with the lowest Akaike Information Criterion (AIC) was considered to have the best fit. Adjusted OR (adj-OR) with $95 \%$ confidence intervals (95\% CIs) have also been calculated for the variables retained in the final model. The significance level fixed for all of the analysis was 0.05 , two-tailed. Data have been analyzed by using the R statistical software package [21].

\section{Results}

\section{Main findings}

A total of 2506 out of 10,854 medical residents $(24.1 \%$ of the sample) have been recruited in the survey. The median age of medical residents involved in the study was 29 (interquartile range $=3$ ). The majority of the respondents were females $(n=1621 ; 64.7 \%)$. Specialty fields more represented were clinical $(1099 ; 43.9 \%)$, followed by diagnostic $(N=840 ; 33.5 \%)$ and surgical $(n=567 ; 22.6 \%)$. Influenza vaccination rate during 2011/2012 season was $11.9 \%$ (data not shown in table) [20].

As reported in Table 1, the training on influenza and influenza vaccination during the postgraduate medical school education was reported as "fair" or "poor" by 1021 study participants $(40.7 \%)$. Similarly, during the postgraduate medical education the training on influenza and its vaccination was reported as "fair" or "poor" by $59.6 \%$ of medical residents $(n=777$ and $n=716$, respectively).

1658 medical residents $(65.8 \%)$ reported to be unaware if their medical tutors during postgraduate medical school were vaccinated against seasonal influenza.
Table 1 Training quality, coworkers attitudes and knowledge towards influenza and influenza vaccination among Italian medical residents

\begin{tabular}{|c|c|c|}
\hline \multirow[t]{2}{*}{ Explored item or dimension } & \multicolumn{2}{|c|}{$n=2,506$} \\
\hline & $\bar{n}$ & (\%) \\
\hline \multicolumn{3}{|c|}{ Training quality on influenza and influenza vaccination during degree } \\
\hline - excellent & 42 & $(1.7)$ \\
\hline- good & 441 & $(17.6)$ \\
\hline - satisfactory & 1,002 & $(40.0)$ \\
\hline - fair & 784 & $(31.3)$ \\
\hline - poor & 237 & $(9.4)$ \\
\hline \multicolumn{3}{|l|}{$\begin{array}{l}\text { Training quality on influenza and influenza vaccination } \\
\text { during post graduate medical school }\end{array}$} \\
\hline - excellent & 49 & $(2.0)$ \\
\hline- good & 303 & $(12.0)$ \\
\hline - satisfactory & 661 & $(26.4)$ \\
\hline - fair & 777 & $(31.0)$ \\
\hline - poor & 716 & $(28.6)$ \\
\hline \multicolumn{3}{|l|}{$\begin{array}{l}\text { Adherence to influenza vaccination among post graduate } \\
\text { medical school tutors }\end{array}$} \\
\hline - $\leq 90 \%$ of tutors & 133 & $(5.3)$ \\
\hline$-\leq 50 \%$ of tutors & 70 & $(2.8)$ \\
\hline$-\geq 25 \%$ of tutors & 509 & $(20.3)$ \\
\hline - none of tutors & 144 & $(5.7)$ \\
\hline - do not know & 1,650 & $(65.8)$ \\
\hline \multicolumn{3}{|l|}{$\begin{array}{l}\text { Adherence to influenza vaccination among other post graduate } \\
\text { medical school MRs }\end{array}$} \\
\hline$-\leq 90 \%$ of $\mathrm{MRs}$ & 53 & $(2.1)$ \\
\hline$-\leq 50 \%$ of MRs & 50 & $(2.0)$ \\
\hline$-\geq 25 \%$ of MRs & 665 & $(26.5)$ \\
\hline - none of tutors & 424 & $(16.9)$ \\
\hline - do not know & 1,314 & $(52.4)$ \\
\hline \multicolumn{3}{|l|}{$\begin{array}{l}\text { Knowledge about the influenza vaccine virus composition for } \\
\text { 2011-2012 season }\end{array}$} \\
\hline - correct information & 593 & $(23.7)$ \\
\hline - erroneous information & 538 & $(21.5)$ \\
\hline - do not know & 1,375 & $(54.8)$ \\
\hline \multicolumn{3}{|l|}{ Main informative sources on influenza vaccination } \\
\hline - none & 1,684 & $(67.2)$ \\
\hline - not interested & 509 & $(20.4)$ \\
\hline $\begin{array}{l}\text { - recommendation of Health Minister/International } \\
\text { Authorities }\end{array}$ & 79 & (3.1) \\
\hline - scientific sources & 109 & (4.3) \\
\hline $\begin{array}{l}\text { - others (mass media, blog, internet, facebook, word of } \\
\text { mouth among HCWs, etc...) }\end{array}$ & 125 & (5.0) \\
\hline
\end{tabular}

At the same time, 1314 medical residents (52.4\%) did not know if their residency colleagues had been vaccinated during influenza season. 
Only $23.7 \%$ of the respondent medical residents $(n=593)$ had knowledge about the correct composition of 2011/2012 seasonal influenza vaccine, whereas $54.8 \%(n=1375)$ did not have this information and $21.5 \%(n=538)$ gave a wrong answer.

The majority of survey sample $(n=1684 ; 67.2 \%)$ did not consider any informative sources on influenza vaccination and, in addition, 509 of them (20.4\%) were not interested in any sources of information.

Factors involved in the decision to get vaccinated during the 2011-2012 influenza season have been analyzed in the multivariable analysis reported in Table 2.

Specialty duty was not significantly associated with influenza vaccination attitude (adjOR for surgical

Table 2 Factors involved in the decision to get vaccinated during 2011-2012 influenza season among Italian MRs $(n=2506)$

\begin{tabular}{|c|c|}
\hline Explored item or dimension & $\begin{array}{l}\text { Vaccine uptake during the } \\
\text { 2011-2012 season }\end{array}$ \\
\hline & Adj OR \\
\hline & (95\% Cls) \\
\hline \multicolumn{2}{|l|}{ Main specialty duties } \\
\hline - clinical & Referent \\
\hline - surgical & $0.92(0.69-1.27)^{d}$ \\
\hline - diagnostic & $1.22(0.85-1.56)^{d}$ \\
\hline \multicolumn{2}{|l|}{$\begin{array}{l}\text { Adherence to } 2011 / 2012 \text { seasonal } \\
\text { influenza vaccination among tutors }\end{array}$} \\
\hline - none of tutors & Referent \\
\hline - do not know & $4.27(1.32-13.75)^{c}$ \\
\hline - yes $(\leq 90 \%, \leq 50 \%, \geq 25 \%)$ & $4.4(1.35-14.26)^{c}$ \\
\hline \multicolumn{2}{|l|}{$\begin{array}{l}\text { Adherence to } 2011 / 2012 \text { seasonal } \\
\text { influenza vaccination among other MRs }\end{array}$} \\
\hline - none of tutors & Referent \\
\hline - do not know & $1.59(0.83-3.06)^{d}$ \\
\hline - yes $(\leq 90 \%, \leq 50 \%, \geq 25 \%)$ & $2.2(1.14-4.23)^{\mathrm{c}}$ \\
\hline \multicolumn{2}{|l|}{$\begin{array}{l}\text { Knowledge about the influenza vaccine } \\
\text { virus composition for 2011-2012 season }\end{array}$} \\
\hline - do not know & Referent \\
\hline - erroneous information & $1.46(0.97-2.21)^{d}$ \\
\hline - correct information & $2.43(1.64-2.58)^{a}$ \\
\hline \multicolumn{2}{|l|}{$\begin{array}{l}\text { Main informative sources on influenza } \\
\text { vaccination }\end{array}$} \\
\hline - not interested & Referent \\
\hline - none & $2.48(1.38-4.45)^{\mathrm{b}}$ \\
\hline $\begin{array}{l}\text { - others (mass media, blog, internet, } \\
\text { facebook, etc...) }\end{array}$ & $1.81(0.77-4.3)^{d}$ \\
\hline $\begin{array}{l}\text { - recommendation of Health Minister/ } \\
\text { International Authorities, scientific } \\
\text { sources }\end{array}$ & $6.96(3.38-14.36)^{\mathrm{a}}$ \\
\hline
\end{tabular}

duties $=0.92 ; 95 \% \mathrm{CI}=0.69-1.27$, adjOR for diagnostic duties $=1.22 ; 95 \% \mathrm{CI}=0.85-1.56$ ).

Adherence to seasonal 2011/2012 influenza vaccination by postgraduate medical school tutors (adjOR $=4.4 ; 95 \%$ $\mathrm{CI}=1.35-14.26)$ and other post graduate medical school medical residents (adjOR $=2.2 ; 95 \% \mathrm{CI}=1.14-4.23$ ) was significantly associated with decision to get vaccinated.

Moreover, influenza vaccination uptake was also related to correct knowledge about the virus composition of 2011/ 2012 influenza vaccine (adjOR $=2.43 ; 95 \% \mathrm{CI}=1.64-2.58)$.

Lastly, medical residents adhering to vaccination during 2011-2012 season reported to be more prone to consult scientific sources or Institutional recommendations (Health Minister, International Health Authorities) on influenza vaccination $(\operatorname{adjOR}=6.96$; $95 \% \mathrm{CI}=3.38-14.36$ ).

\section{Discussion}

\section{Interpretation}

A proper medical education, both during degree and postgraduate medical school, is vital for the acquisition of adequate professional attitudes and knowledge on preventive choices, based on evidence-based prevention principles [22]. Medical residency represents an opportunity to implement educational and training interventions, aimed at promoting appropriate professional behaviors and modifying inappropriate ones. Unfortunately, our study shows that in Italy, the vaccination coverage against seasonal influenza among medical residents is far below the recommended rates, exactly as observed among other health care workers. Given the documented low influenza vaccination coverage, medical residents represent potential influenza carriers to the patients, especially particularly debilitated subjects and those at risk of hospital-related complications (immunocompromised patients, the elderly, children, pregnant women, etc.) [23].

Thus, medical residents could be considered as a core target group specific educational interventions.

The efficacy of educational and training interventions for improving medical residents' attitudes towards influenza vaccination has already been proven in different geographic settings [24].

However, our results highlight some other determinants that could play a key role in promoting influenza vaccination compliance. The first of these determinants is specific knowledge on the topic; in Italy, this appears to be as inadequate as the influenza vaccination coverage [25].

In fact, more than $30 \%$ of the medical residents who took part in our study stated that they had received unsatisfactory training on influenza and vaccination against it, both during medical school and postgraduate courses. Our results suggest that the inadequate training during medical residency reported by $30 \%$ of respondents could be a contributing factor responsible for the finding 
that three out of four respondents either did not know or erroneously identified the vaccine virus composition. Moreover, just over $7 \%$ of the medical residents referred to scientific sources or Institutional recommendations (Health Ministry, American and European Centers for Disease and Control), while indifference prevailed.

Intriguingly, both being aware of the actual composition of the influenza vaccine and consulting scientific informative sources were significantly associated with a greater compliance with influenza vaccination uptake, also after adjustment.

These findings seem to suggest that accurate information about influenza vaccine should be considered as an independent factor associated with higher vaccination coverage among young physicians. Furthermore, our study documents an insufficient education regarding the importance of the vaccine during both undergraduate and postgraduate studies.

All of the previous evidence could also explain why more than half of respondents felt that they should attend multidisciplinary ad hoc courses to improve their knowledge on influenza and vaccinating against it, as reported in a previous paper [20].

Most hospitals/health systems in the US and overseas are implementing a mandatory influenza vaccination protocol and have moved away from voluntary vaccination programs for health care workers, so these results can no longer be generalized. Nevertheless, our data demonstrate that neither mandatory vaccination nor incentives for vaccination are considered as realistic options by the Italian medical residents to implement vaccination adherence, confirming possible ethical and legal consequences and noticeable application difficulties within certain contexts [20,26-28].

However, having specific knowledge on the topic is not the only factor positively associated with influenza vaccination compliance; an important role is also played by the general work environment. As shown by the multivariable analysis, a proactive coworker attitude, especially involving the tutors (but also among residency colleagues), could represent a key aspect associated with an increased vaccine coverage among health care workers [29].

\section{Limitations}

Major limitations affecting the present study are essentially three. Firstly, the respondents included in the study were only about a quarter of the targeted cohort, so the results are not representative of the majority. Moreover, the low response rate $(24.1 \%)$ could be indicative of a selection bias, since respondents with positive personal attitude to influenza vaccination may have predominantly responded to the survey.

Finally, although all the data used in our study were collected anonymously, a potential residual social desirability bias cannot be excluded. However, the consistency between results and vaccination rates documented in the different Italian Regions and different specialty duties lead us to conclude that these possible limitations only marginally affect the results of the study. Furthermore, the influenza vaccination uptake rate is coherent with previous studies conducted among health care workers $[6,18,30]$.

Despite of the potential limitations discussed above, this is the first study carried out in Europe that analyzes, on a national level, the impact of a proper training and a favorable work environment on influenza vaccination uptake among young physicians in training.

\section{Conclusions}

According to the recommendations of the American National Vaccine Advisory Committee, stating that "Health Care Employers and facilities should establish comprehensive influenza infection prevention programs that include education of Health Care Personnel as a key component", our study confirms the need of appropriate training and education in order to improve physicians' attitudes towards influenza vaccination [31].

The analysis of the collected data suggests some strategies that could be implemented in order to increase influenza vaccination coverage among medical residents. A valid approach could be organizing educational activities on the importance of influenza vaccination, specifically for single operating units (medical doctors, nurses and medical residents), with a selected audience of subjects sharing the work environment [22, 24].

Furthermore, an improved promotion of web sites and institutional informative sources for influenza and the relative vaccination could be considered as well, for example during the training meetings and through hanging flyers in the operating units [32].

In conclusion, university training on influenza and vaccination programs could be improved by defining multidisciplinary shared educational pathways, and by organizing training courses on the subject during postgraduate courses, with the common aim to improve knowledge and to encourage proactive attitudes of the "future doctors" towards influenza vaccination, certifying it as an evidence-based public heath strategy in preventing hospital-acquired infections. Moreover, future health care providers should be equipped with not just the knowledge, but also the skills in counseling patients regarding the importance of vaccination.

\footnotetext{
Competing interests

All authors report no competing interest (political, personal, religious, ideological,
} academic, intellectual, commercial or any other) relevant to this article.

Authors' contributions

CC have made substantial contributions to conception and design of the study, acquisition, analysis and interpretation of data. WM have been 
involved in drafting the manuscript or revising it critically for important intellectual content. EA have made contributions to conception and design of the study and data analysis. FV have given final approval of the version to be published. GC have made contributions to conception and design of the study. All authors read and approved the final manuscript.

\section{Acknowledgements}

The Italian Medical Residents Influenza Vaccination working group and project do not receive any financial support. The authors are fully indebted to Dr. Johanna Miettinen for the language copy-editing of the manuscript. The authors are grateful to all the members of working group (Elena Azzolini, Cesare Baldini, Margherita Bergomi, Alessio Daniele Biafiore, Manuela Bianco, Lucia Borsari, Paolo Cacciari, Chiara Cadeddu, Paola Camia, Eugenia Carluccio, Andrea Conti, Chiara De Wauree, Valentina Di Gregori, Leila Fabiani, Roberto Fallico, Barbara Filisetti, Maria E Flacco, Elisabetta Franco, Roberto Furnari, Veronica Galis, Maria R Gallea, Maria F Gallone, Serena Gallone, Umberto Gelatti, Francesco Gilardi, Anna R Giuliani, Orazio C Grillo, Nicolò Lanati, Silvia Mascaretti, Antonella Mattei, Rocco Micò, Laura Morciano, Giuseppe Napoli, Nicola Nante, Carmelo Nobile, Raffaele Palladino, Salvatore Parisi, Marika Passaro, Gabriele Pelissero, Lucia Pennacchietti, Michele Quarto, Alessandra Ricciardi, Walter Ricciardi, Gabriele Romano, Anita Saponari, Francesco S Schioppa, Carlo Signorelli, Roberta Siliquini, Valeria Trabacchi, Maria Triassi, Alessia Varetta, Andrea Ziglio, Angela Zoccali).

Received: 13 January 2015 Accepted: 23 January 2016

Published online: 29 January 2016

\section{References}

1. WHO. Influenza (seasonal) fact sheet number 211. 2009. Available at: http://www.who.int/mediacentre/factsheets/fs211/en/. (last accessed: 29/01/2016).

2. Bénet T, Régis $C$, Voirin N, Robert $\mathrm{O}$, Lina B, Cronenberger S, et al. Influenza vaccination of healthcare workers in acute-care hospitals: a case-control study of its effect on hospital-acquired influenza among patients. BMC Infect Dis. 2012;1(12):30.

3. $\mathrm{Ng}$ AN, Lai CK. Effectiveness of seasonal influenza vaccination in healthcare workers: a systematic review. J Hosp Infect. 2011;79:279-86.

4. Music T. Protecting patients, protecting healthcare workers: a review of the role of influenza vaccination. Int Nurs Rev. 2012;59(2):161-7.

5. Ciancio BC, Rezza G. Costs and benefits of influenza vaccination: more evidence, same challenges. BMC Public Health. 2014;14:818.

6. Jiménez-García R, Rodríguez-Rieiro C, Hernandez-Barrera V, Carrasco Garrido P, López de Andres A, Esteban-Vasallo MD, et al. Negative trends from 2008/9 to 2011/12 seasons in influenza vaccination coverages among high risk subjects and health care workers in Spain. Vaccine. 2014;32(3):350-4

7. Centers for Disease Control and Prevention. Novel H1N1 Flu: facts and figures. 2009. Available at: http://www.cdc.gov/h1n1flu/surveillanceqa.htm. (last accessed: 29/01/2016)

8. European Centre for Disease Prevention and Control. Why healthcare workers are a priority group for pandemic influenza $A(\mathrm{H} 1 \mathrm{~N} 1)$ vaccination? 6 October 2009. Available at: http://ecdc.europa.eu/en/activities/sciadvice/_ layouts/forms/Review_DispForm.aspx?List=a3216f4c-f040-4f51-9f77a96046dbfd72\&ID=119.12 (last accessed: 29/01/2016)

9. Amodio E, Tramuto F, Maringhini G, Asciutto R, Firenze A, Vitale F, et al. Are medical residents a "core group" for future improvement of influenza vaccination coverage in health-care workers? A study among medical residents at the University Hospital of Palermo (Sicily). Vaccine. 2011;29:8113-17.

10. Costantino C, Amodio E, Vitale F, Maida C, Maringhini G, Asciutto R, et al. Attitudes, behaviours and perceptions of Italian General Practitioner trainees towards influenza vaccination in Western Sicily (Italy). Ital J Public Health 2012;9:33-9.

11. Bishburg E, Shah M, Mathis AS. Influenza vaccination among medical residents in a teaching hospital. Infect Control Hosp Epidemiol. 2008;29:89-91.

12. Silveira MB, Perez DA, Yamaguti A, Saraiva EZ, Borges MG, Moraes-Pinto Ml. Immunization status of residents in pediatrics at the Federal University of São Paulo, Brazil. Rev Inst Med Trop Sao Paulo. 2011:53:73-6.

13. Mir O, Adam J, Gaillard R, Gregory T, Veyrie N, Yordanov Y, et al. Vaccination coverage among medical residents in Paris, France. Clin Microbiol Infect. 2012;18:E137-139.

14. Bentele H, Bergsaker MR, Hauge SH, Bjørnholt JV. Vaccination coverage for seasonal influenza among residents and health care workers in Norwegian nursing homes during the 2012/13 season, a cross-sectional study. BMC Public Health. 2014;14:434.

15. Lim YC, Seale H. Examining the views of key stakeholders regarding the provision of occupational influenza vaccination for healthcare workers in Australia. Vaccine. 2014;32:606-10.

16. Galanakis E, Jansen A, Lopalco PL, Giesecke J. Ethics of mandatory vaccination for healthcare workers. Euro Surveill. 2013;18:20627.

17. Isaacs D, Leask J. Should influenza immunisation be mandatory for healthcare workers? No. BMJ. 2008:337:a2140.

18. Mena G, Llupià A, García-Basteiro AL, Sequera VG, Aldea M, Bayas JM, et al. Educating on professional habits: attitudes of medical students towards diverse strategies for promoting influenza vaccination and factors associated with the intention to get vaccinated. BMC Med Educ. 2013;13:99.

19. Bouadma L, Barbier F, Biard L, Esposito-Farèse M, Le Corre B, Macrez A, et al. Personal decision-making criteria related to seasonal and pandemic $\mathrm{A}(\mathrm{H} 1 \mathrm{~N} 1)$ influenza-vaccination acceptance among French healthcare workers. PLoS One. 2012;7:e38646.

20. Costantino C, Mazzucco W, Azzolini E, Baldini C, Bergomi M, Biafiore AD, et al. Influenza vaccination coverage among medical residents: An Italian multicenter survey. Hum Vaccin Immunother. 2014;10(5):1204-10.

21. R Development Core Team. $R$ statistical software package, version 2.2.0. 2005. Available at: https://www.r-project.org/. (last accessed: 29/01/2016).

22. Burgess A, Oates K, Goulston K. Role modelling in medical education: the importance of teaching skills. Clin Teach. 2015. doi: 10.1111/tct.12397.

23. Amodio E, Restivo V, Firenze A, Mammina C, Tramuto F, Vitale F. Can influenza vaccination coverage among healthcare workers influence the risk of nosocomial influenza-like illness in hospitalized patients? J Hosp Infect. 2014;86:182-7.

24. Afonso N, Kavanagh M, Swanberg S. Improvement in attitudes towards influenza vaccination in medical students following an integrated curricular intervention. Vaccine. 2014:32:502-6.

25. Amodio E, Tramuto F, Costantino C, Restivo V, Maida C, Calamusa G, et al. Diagnosis of influenza: only a problem of coding? Med Princ Pract. 2014;23:568-73

26. Helms CM, Polgreen PM. Should influenza immunization be mandatory for healthcare workers? Yes. BMJ. 2008;337:a2142.

27. Babcock HM, Gemeinhart N, Jones M, Dunagan WC, Woeltje KF. Mandatory influenza vaccination of health care workers: translating policy to practice. Clin Infect Dis. 2010;50:459-64

28. Anikeeva O, Braunack-Mayer A, Rogers W. Requiring influenza vaccination for health care workers. Am J Public Health. 2009:99:24-9.

29. Jacobson JA. Residents' role in immunizing adults: rationale, opportunity, obstacles, and strategies. Virtual Mentor. 2012;14:23-9.

30. National Vaccine Advisory Committee. Strategies to achieve the healthy people 2020 annual influenza coverage goal for health-care personnel: recommendation from the national vaccine advisory committee. Public Health Rep. 2013;128:7-25

31. Costantino C, Battaglia A, D'Asta M, Furnari F, Gimigliano A, Guaccero A, et al. Knowledge, attitudes and behaviors regarding influenza vaccination among Hygiene and Preventive Medicine residents in Calabria and Sicily. Euromediterranean Biomed J. 2012;7:77-83.

32. Hollmeyer $\mathrm{H}$, Hayden $F$, Mounts $A$, Buchholz U. Review: interventions to increase influenza vaccination among healthcare workers in hospitals. Influenza Other Respir Viruses. 2013;7:604-21.

\section{Submit your next manuscript to BioMed Central and we will help you at every step:}

- We accept pre-submission inquiries

- Our selector tool helps you to find the most relevant journal

- We provide round the clock customer support

- Convenient online submission

- Thorough peer review

- Inclusion in PubMed and all major indexing services

- Maximum visibility for your research

Submit your manuscript at www.biomedcentral.com/submit 